
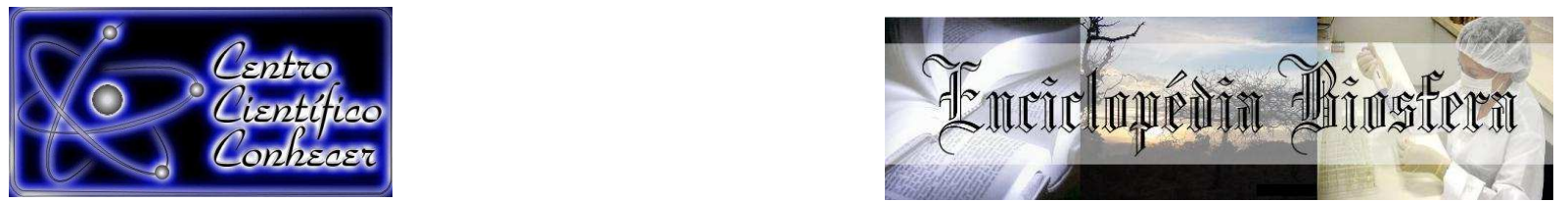

\title{
O GENERO GEONOMA WILLD. NA REGIÃO DO ALTO JURUÁ, EXTREMO OCIDENTAL DO BRASIL
}

\author{
Maria Cristina de Souza ${ }^{1}$, João Damaceno Filho ${ }^{2}$, Jayne Guimarães Ferreira ${ }^{3}$, Karen \\ Caroline Mendonça ${ }^{4}$, Raphaela Bomfim de Oliveira ${ }^{5}$ \\ ${ }^{1}$ Professora Doutora da Universidade Federal do Acre, Cruzeiro do Sul, Acre, Brasil \\ (mcs122005@yahoo.com.br) \\ ${ }^{2-4}$ Graduados em Ciências Biológicas pela Universidade Federal do Acre, \\ Cruzeiro do Sul, Acre, Brasil \\ ${ }^{5}$ Professora Especialista do Instituto Federal do Acre, Cruzeiro do Sul, Acre,Brasil
}

Recebido em: 08/04/2017 - Aprovado em: 10/06/2017 - Publicado em: 20/06/2017 DOI: 10.18677/EnciBio_2017A77

\begin{abstract}
RESUMO
Geonoma é um gênero neotropical que tem como um dos centros de diversidade a bacia amazônica. Trata-se de palmeiras que ocupam o sub-bosque da floresta, conhecidas popularmente por ubim, ubim-do-céu, falso-ubim, entre outros. O presente trabalho objetivou levantar o seu estado de coleta visando atualização de dados referente a Região do Alto Juruá. Excursões foram realizadas de 2010 a 2014 a cinco municípios acreanos (Marechal Thaumaturgo, Porto Walter, Cruzeiro do Sul, Rodrigues Alves e Mâncio Lima) coletando o material botânico e submetendo ao processo de herborização, identificação e incorporação ao Herbário do Campus Floresta (HUFACCZS) da Universidade Federal do Acre, de acordo com os procedimentos usuais em sistemática vegetal. Foram identificadas cinco espécies e duas subespécies: Geonoma leptospadix Trail.; G. maxima subsp. chelidonura (Spruce) A. Hend.; G. macrostachys Mart. com três morfotipos; G. brongniartii Mart.; G. camana; G. deversa (Poit.) Kunth, G. stricta subsp. piscicauda Dammer. Os dados obtidos ampliaram a coleção de Geonoma para Região, refazendo coletas e registrando sua ocorrência para novas localidades. Notas sobre as variações morfológicas observadas no campo e ilustrações são acrescentadas.
\end{abstract}

PALAVRAS-CHAVE: Amazônia Ocidental. Taxonomia, ubim.

\section{THE GENERA GEONOMA WILLD. IN THE HIGH JURUÁ REGION, WEST EXTREME OF BRAZIL}

\begin{abstract}
Geonoma is a neotropical genus that has as one of the centers of diversity the Amazon basin. These are palm trees that occupy the understory of the forest, popularly known as ubim, ubim-do-ceu, falso-ubim, among others. The present work aimed to raise its collection status in order to update data referring to the Upper Juruá Region. The tour was carried out from 2010 to 2014 to five Acre counties (Marechal Thaumaturgo, Porto Walter, Cruzeiro do Sul, Rodrigues Alves and Mâncio Lima), collecting the botanical
\end{abstract}


material and submitting to the process of herborization, identification and incorporation into the Herbarium of Campus Floresta (HUFAC- CZS) of the Federal University of Acre, according to the usual procedures in plant systematics. Five species and two subspecies were identified: Geonoma leptospadix Trail.; G. maxima subsp. chelidonura (Spruce) A. Hend.; G. macrostachys Mart. with three morphotypes; G. brongniartii Mart., G. camana; G. deversa (Poit.) Kunth, G. stricta subsp. Dammer piscicauda. The obtained data extended the collection of Geonoma to Region, not only remaking collections but recording their occurrence to new locations. Notes on morphological variations in the field and illustrations are added.

KEYWORDS: Ubim, taxonomy, Western Amazon.

\section{INTRODUÇÃO}

A Região do Alto Juruá localizada no extremo ocidental do Brasil compreende uma das maiores biodiversidades do planeta (BROWN Jr \& FREITAS, 2002; DALY \& SILVEIRA, 2008; ANJOS et al. 2013) e as Arecaceae, conhecidas popularmente por palmeiras, fazem parte desse contexto se destacando na paisagem de forma expressiva, não só pelas preferências de ambiente, mas também e principalmente pelo seu aproveitamento pela população local. São assinaladas para esta Região 22 gêneros e 49 espécies aproximadamente (DALY \& SILVEIRA, 2008, LORENZI et al. 2010).

Os autores mencionados, entre outros (HENDERSON et al. 1995; LORENZI et al. 2010; HENDERSON, 2011), ampliaram consistentemente os dados sobre tais plantas, mas verifica-se mediante consultas aos herbários de referência que o número de coletas feitas na Região ainda é baixo e que muitas localidades estão mal representadas; ou ainda algumas identificações recentes foram feitas com base em material antigo e insuficiente, e precisam de atualizações.

O gênero Geonoma é um exemplo, neotropical, representado por palmeiras que ocupam o sub-bosque das florestas, principalmente a floresta tropical úmida, está subamostrado, já que as coletas feitas ali foram em sua maioria entre as décadas de 70 e 90 e restritas a algumas localidades, mesmo sendo palmeiras desprovidas de espinhos e de pequeno porte (HENDERSON, 2011).

No que se refere a sua morfologia, algumas das espécies são de fácil reconhecimento no campo, outras são confundidas com as do gênero Hyospathe, Chamaedorea e até com Bactris, que apesar da presença de espinhos, esses, às vezes, são tão sutis, quase imperceptíveis, que os erros de identificação nos herbários são comuns. Além disso, os caracteres morfológicos de Geonoma são bastante variáveis, o que amplia a possibilidade de erro na identificação (HENDERSON et al., 1995; LORENZI et al., 2010).

As tentativas de entender tais variações, ora ampliando o número de espécies (BURRET, 1930; WESSELS BOER, 1968), ora reduzindo ou fazendo novas combinações (HENDERSON, 1995; HENDERSON et al. 1995; HENDERSON, 2011) têm se repetido, com algumas delas indefinidas, e que leva a supor que aumentar 0 esforço de coleta seja a solução.

LORENZI et al. (2010), mantêm muitos dos critérios adotados por WESSELS BOER (1968) na delimitação de espécie. HENDERSON (2011) por sua vez, quantificou tais variações, e chama a atenção para exemplares incompletos, sinonimizando muitas 
das espécies que se desconhecia o material Tipo. Outros (tais como SOARES et al., 2014), defendem a intensificação de estudos e uso de ilustrações na ausência do material Tipo.

Diante do exposto, o objetivo desse trabalho foi verificar o estado de coleta do gênero Geonoma para a região do Alto Juruá, atualizando dados e ampliando o conhecimento da flora local.

\section{Área de estudo}

\section{MATERIAL E MÉTODOS}

O local de estudo foi a Região do Alto Juruá, no extremo ocidental do Brasil (FIGURA 1). Ali estão instalados as margens do Rio Juruá e seus afluentes seis municípios acreanos (Mâncio Lima, Cruzeiro do Sul, Rodrigues Alves, Porto Walter e Marechal Thaumaturgo) e um amazonense (Guajará), selecionados por comporem uma das maiores biodiversidades do planeta, cuja pesquisa está vinculada a um projeto em andamento: "Flora da Região do Alto Juruá, extremo ocidental do Brasil". Excursões foram realizadas entre 2010 e 2014, coletando amostras nos referidos municípios e conduzindo ao Laboratório de Taxonomia Vegetal da Universidade Federal do Acre em Cruzeiro do Sul, para herborização. Em seguida foi feita a identificação pela primeira autora, botânica, especialista em Arecaceae, e levantado o estado de coleta para cada espécie registrada, com apoio de literatura especializada (RIBEIRO et al., 1999; DALY \& SILVEIRA, 2008; LORENZI et al., 2004; 2010, HENDERSON, 2011), consulta a banco de dados (inct.splink.org.br) e herbários virtuais nacionais e estrangeiros (www.jbrj.gov.br; www.mobot.org; www.nybg.org; www.mnhn.fr; www.inpa.gov.br; www.kew.org). A escolha dos referidos herbários foi por serem os principais depositários das coleções das grandes expedições feitas entre os séculos XIX e XX. As abreviaturas dos Herbários são de acordo com HOLMGREN et al., (1990). A validação dos nomes científicos foi feita com base no último tratamento taxonômico (HENDERSON, 2011). Abreviaturas usadas no texto tais como, s.l, s.d, s.n, significam sem localidade, sem data, sem número, respectivamente. O material coletado foi incorporado ao Herbário do Campus Floresta (UFAC-HCZS), extensão da Universidade Federal do Acre em Cruzeiro do Sul.

\section{RESULTADOS E DISCUSSÃO}

O estudo permitiu o registro de cinco espécies e duas subespécies pertencentes ao gênero Geonoma, com atualizações importantes, uma vez que a referida Região se destaca pela diversidade e pelo difícil acesso. O estado de coleta bem como anotações, referentes às variações das plantas no campo e ilustrações complementam a pesquisa.

1. Geonoma leptospadix Trail. Journal of Botany, British and Foreign 14: 32, pl.183, f. 2. 1876. (J.Bot.). Tipo (Isótipo): Brasil. Amazonas: Tonantins, 24.II.1874, J.W.H. Trail 963/CLXXII (P) Fig. 2A

Palmeira $30 \mathrm{~cm}$ alt. Estipe solitário. Folhas, 18, inteiras, $16 \mathrm{~cm}$ compr., $8 \mathrm{~cm}$ larg., bifurcadas no ápice. Inflorescência interfoliar ramificada de $1^{\underline{a}}$ ordem. Raquilas, 3, por pedúnculo, verde-amareladas, ou vermelha alaranjadas na fase de infrutescência; alvéolos alternos, distantes um do outro $1-1,5 \mathrm{~cm}$ compr. Frutos redondos, pequenos, 6- $7 \mathrm{~mm}$ compr., 6 - 6,5 mm larg., preto-amarronzados quando maduros.

ENCICLOPÉDIA BIOSFERA, Centro Científico Conhecer - Goiânia, v.14 n.25; p.962 
Material adicional: Brasil. Acre, Cruzeiro do Sul, Campus Floresta/UFAC, SOUZA, M.C. 589 et. al., 02.V.2011, fr.

Estado de coleta: Palmeira rara na Região do Alto Juruá, nessa pesquisa foi encontrada apenas no município de Cruzeiro do Sul, sendo o primeiro registro para tal município, contrariando relatos anteriores (LORENZI et al., 2004; DALY \& SILVEIRA, 2008) que afirmam sua ocorrência ali, bem como para Mâncio Lima e Porto Walter. Entretanto, esses autores se referem a apenas dois espécimes procedentes de Mâncio Lima (BANDEIRA, J. 21; FERREIRA, E. 186), nenhum deles oriundo de Porto Walter e Cruzeiro do Sul. As consultas aos herbários virtuais confirmam apenas os dois mencionados, evidenciando a necessidade de ampliar o esforço de coleta, tendo em vista que muitas localidades foram inacessíveis e a extensão da Região (Figura 1).

A espécie é bem definida morfologicamente no local, encontrada no sub-bosque como as demais, em terra firme (Figura 2A) Se distinguindo fácil, não só pela altura, muito pequena, $30 \mathrm{~cm}$ (os demais espécimes consultados nos herbários não passaram de $1,5 \mathrm{~m}$ de altura), mas também e principalmente porque na inflorescência a distância entre os alvéolos é marcante em relação a outras espécies; além disso, as folhas, inteiras, bífidas, que se repetiram em todo material consultado proveniente da localidade, mantendo o padrão observado no Tipo (TRAIL, J.W.H. 963) e nos demais espécimes da Amazônia Ocidental (tal como, FERREIRA, E. 186), confirmando o que HENDERSON (2011) defende. Diferente do que ocorre na Amazônia oriental, cujos exemplares coletados no estado do Amapá (IRWIN, H.S. 47351, 47795, 47631, 48082; MORI, S.A. 17204; RABELO, B.V. 2393; EGLER, W. 46691) apresentam folhas pinadas e que $\mathrm{H}$ (2011) chama a atenção para as semelhanças com G. deversa (Poit.) Kunth.

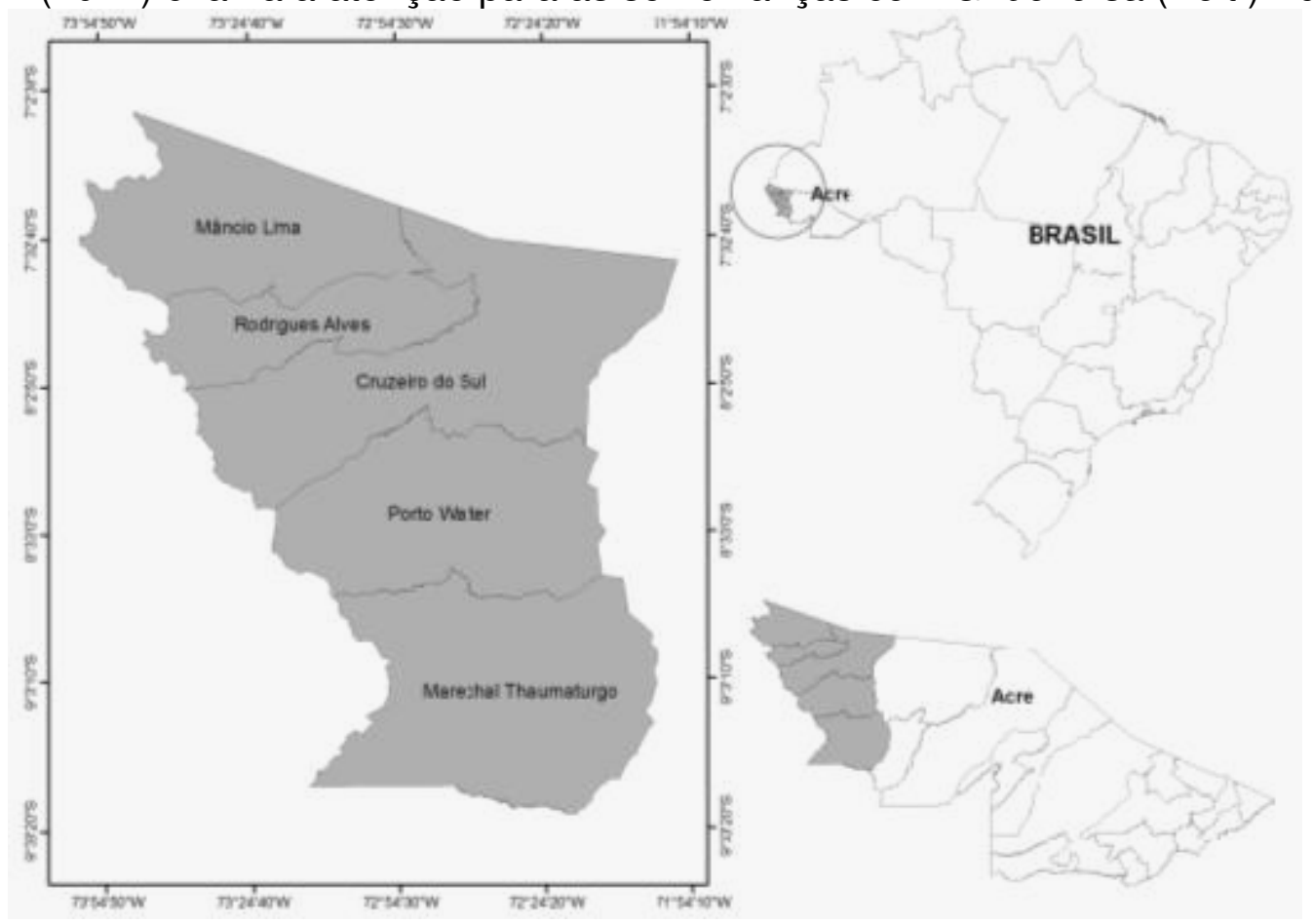

FIGURA 1. Região do Alto Juruá, estado do Acre. Municípios visitados. Fonte: MARLO, 2014. 
2. Geonoma maxima subsp. chelidonura (Spruce) A. Hend. Phytotaxa 17: 99, f. 25. 2011. Basiônimo: Geonoma chelidonura. Journal of the Linnean Society, Botany 11: 111. 1871. (J. Linn. Soc., Bot.). Tipo: Brasil. Amazonas: Rio Uaupés, Novembro 1852, R. Spruce $73(\mathrm{~K})$.

Palmeira 2 - $3 \mathrm{~m}$ alt. Estipe solitário ou cespitoso, 2,5 - $7 \mathrm{~cm}$ circ. Folhas, 9, pinadas, duas por lado, pina basal $60 \mathrm{~cm}$ compr., $4,2 \mathrm{~cm}$ larg. Ângulo, $6^{\circ}-10^{\circ}$; presença às vezes de um par de pinas intermediárias, estreitas, $8 \mathrm{~mm}$ larg. (Figura 3B). O formato das pinas é variável, de retas a sigmoides. Raque, 9 - $39 \mathrm{~cm}$ compr., triangular em corte transversal. Pecíolo $59 \mathrm{~cm}$ compr.; bainha $10 \mathrm{~cm}$ compr.; nervuras abaxiais, raque e pecíolo cobertos por tomento marrom. Inflorescência ramificada de 1‥ ordem; Ráquilas, 10 - 23, vermelhas, ráquila basal, $14 \mathrm{~cm}$ compr. Brácteas: externa e interna, $12 \mathrm{~cm}$ compr. Alvéolos, alternos, $1-5 \mathrm{~mm}$ distantes um do outro. Fruto oval, 1,8 cm compr., 3 mm diâm., verde-amarelado imaturo e preto quando maduro. Figura 2B-C.

Material adicional: Brasil, Acre, Mâncio Lima, Terra dos Poyanaua, SOUZA, M.C. et al. 546, 22.I.2010, fr.; AGUIAR, J.F. et al. 01 e 02, 30.XI.2010, fr.; Cruzeiro do Sul, Assentamento Santa Luzia, SOUZA, M.C. et al. 569, 17.XII.2010, fr., Cruzeiro do Sul, Ramal 3, SILVA, L.C. s/n. 08.V.2012 fr. Cruzeiro do Sul, Canela Fina, RODRIGUES, A. 08, 25.II.2014, fr.

Estado de coleta: a partir desse estudo é que a subespécie em questão foi registrada pela primeira vez para Cruzeiro do Sul. As consultas aos herbários revelaram sua ocorrência apenas para Mâncio Lima (HENDERSON, A 1712, 1122, 1687,1149; LORENZI, H. 3718). Verificou-se que há muitos locais mal representados o que requer a continuidade do levantamento (Figura 1 e 2B-C).

A planta pode ser encontrada tanto em terra firme como em locais ocasionalmente alagados. As discussões em função das variações morfológicas, principalmente das folhas têm posicionado esse táxon em várias categorias, sendo antes reconhecida como espécie (WESSELS BOER,1968), depois como variedade (HENDERSON et al, 1995; LORENZI et al, 2010) e mais recentemente como subespécie (HENDERSON, 2011). Além disso, foi identificada no passado para muitas localidades do Acre como sendo Geonoma juruana Dammer (FERREIRA, E. 244, 272, 443; BANDEIRA, J. 78, entre outros) e que segundo LORENZI et al (2010) e HENDERSON (2011) se trata de sinônimo da subespécie encontrada.

G. maxima subsp. chelidonura pode ainda ser confundida com Hyospathe elegans Mart. (Figura 2D-E). O fato dessa última, ocorrer também no sub-bosque, a semelhança nas folhas e inflorescência, bem como a ausência de espinhos em ambas confundem no campo os menos conhecedores das variações, verificando-se comumente erros de identificação nos herbários. 


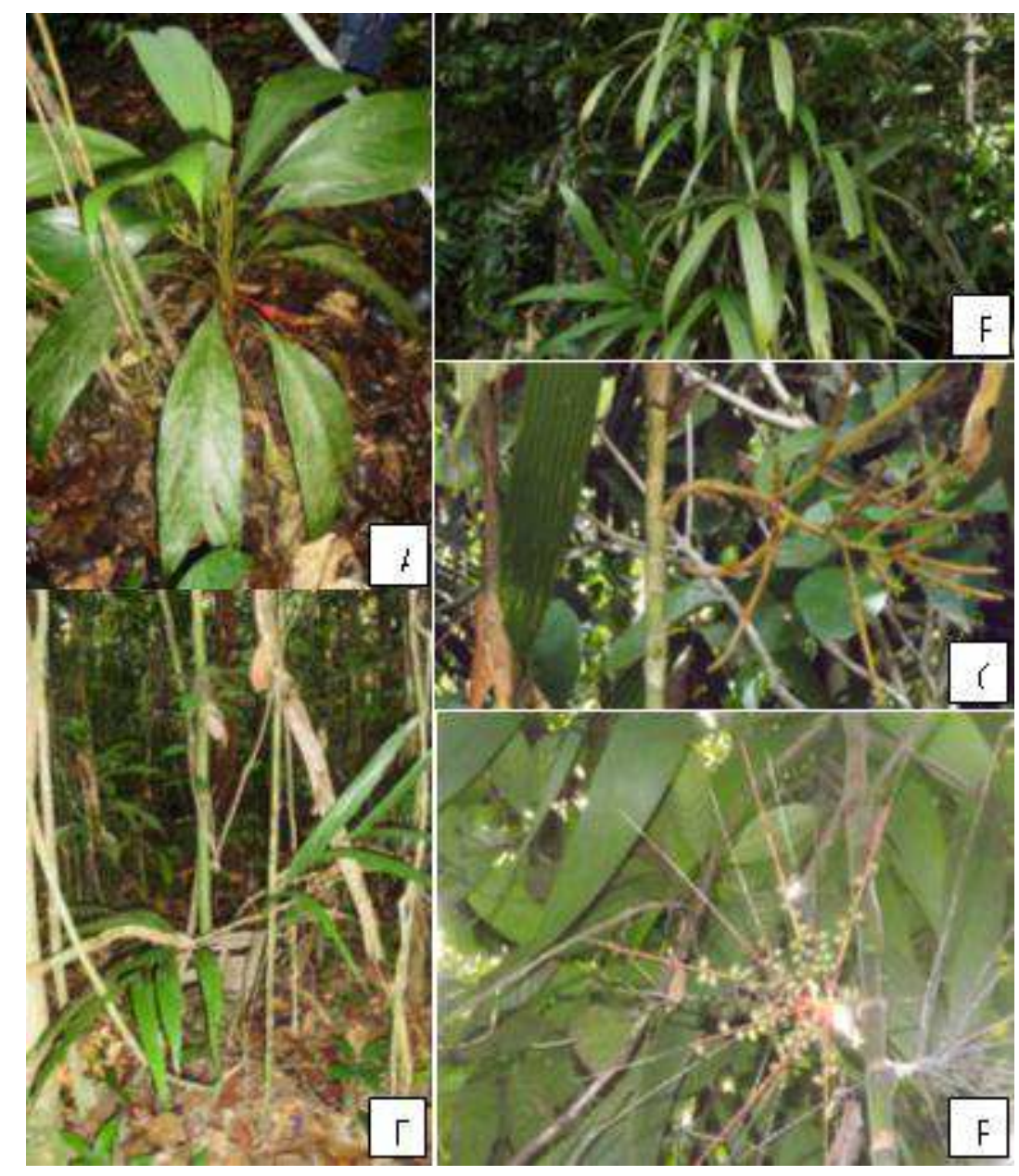

FIGURA 2. A) Geonoma leptospadix, hábito e infrutescência; B-C) Folhas e Infrutescência de Geonoma maxima subsp. chelidonura; D-E) Folhas e Infrutescência de Hyospathe elegans.

3. Geonoma macrostachys Mart. Historia Naturalis Palmarum 2: 19, pl. 20.1823 (Hist. Nat. Palm.). Tipo: Peru. s.l., s.d; Poeppig s.n.(W). Holótipo: Brasil. Amazonas: Rio Japurá, Martius s.n. (M).

As variações morfológicas dessa espécie, a ocorrência de densas populações e muito próximas, chamam a atenção localmente e dificultam sua identificação, concordando com HENDERSON (2011). Foram reconhecidos três morfotipos, caracterizados a seguir. Figuras 3-5.

Morfotipo I: Palmeira acaule. Folhas inteiras, bifurcadas na parte apical, $175-250 \mathrm{~cm}$ compr.; ângulo, 3ㅇ; raque $124 \mathrm{~cm}$ compr. Face abaxial com tomento marrom ao longo das nervuras, adaxial geralmente recoberta parcialmente por liquens. Infrutescência espigada, pedúnculo, 65 - $106 \mathrm{~cm}$ compr., bráctea $1,5 \mathrm{~cm}$ compr., ráquila, $26,5-34 \mathrm{~cm}$ 
compr., alvéolos numerosos, distantes $1,5 \mathrm{~mm}$, um do outro, dispostos em espiral. Frutos, 16, $8 \mathrm{~mm}$ compr., $6 \mathrm{~mm}$ diâm., imaturos verdes, maduros pretos. Figura 3A-C.

Material adicional: Brasil: Acre, Cruzeiro do Sul, Assentamento Santa Luzia, SOUZA, M.C. et al., 553, 563, 12.III.2010, fr.; MENDONÇA, K.C.B. 03 e 04, 18.II.2011, fr.; ALVES, F. 10, 03.XI.2011, fr.; BOMFIM, R. et al. 53, 93, 24.V.2011, fr.

Estado de coleta: nesse trabalho, a palmeira foi encontrada apenas no município de Cruzeiro do Sul (Figura 1), na terra firme, sendo um morfotipo de pouca ocorrência, mediante as várias caminhadas dentro da mata. Mas ainda assim por ser uma região com muitas localidades, ora alagadas, muitos "paranás" "ramais" de difíceis acessos, é importante envidar esforços em revisitá-los. Consultas aos herbários de referência revelaram apenas duas coletas no Alto Juruá e de mesma procedência (CROAT, 62312; JANGOUX, J.J. 8502). É possível que ela esteja mal representada, por ser uma extensa Região de mata pouco alterada e enquadrar seis municípios.

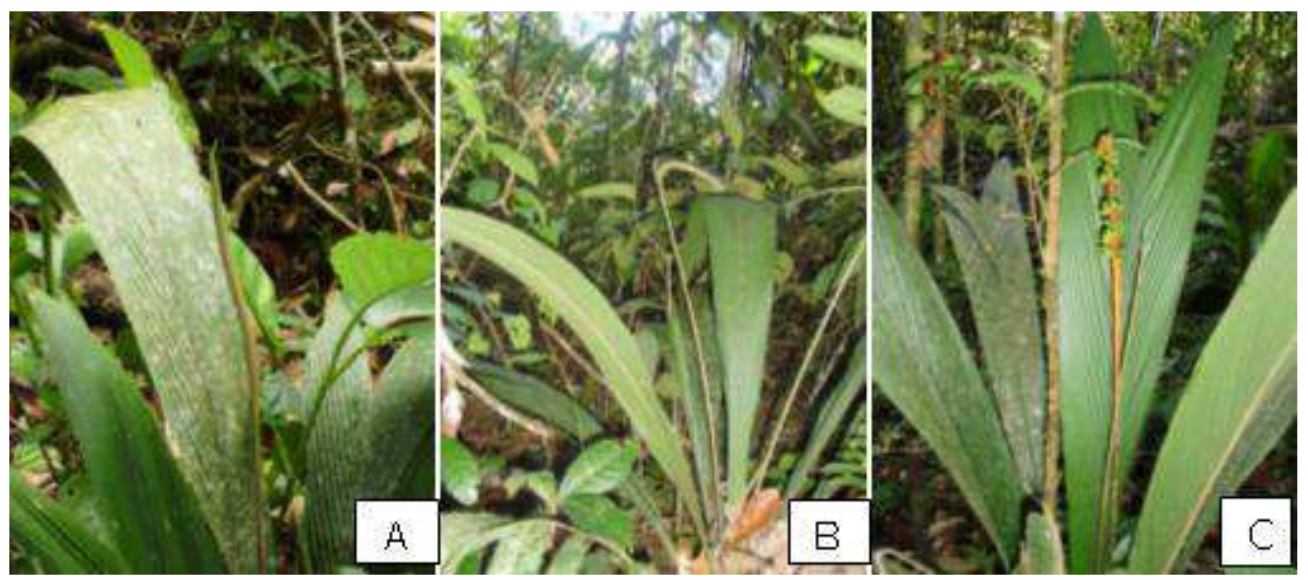

FIGURA 3. Geonoma macrostachys. Morfotipo I. A-B) Hábito e variações na forma da inflorescência; C) Infrutescência.

Morfotipo II. Palmeira de sub-bosque, acaule, folhas, 11, bainha $12,5 \mathrm{~cm}$ compr.; três pinas por lado, raramente quatro, sigmóides; pina basal, larga, 17 - 30,5 cm compr., 4,5 - 6,5 cm de largura, ângulo, 15‥ As pinas basais sempre mais estreitas que as demais, aumentando gradativamente. Tomento marrom, principalmente na face abaxial; Inflorescência espigada, bráctea externa, $12,5 \mathrm{~cm}$ compr., bráctea interna, $32,5 \mathrm{~cm}$ compr., pedúnculo, $26 \mathrm{~cm}$ compr.; ráquila, $18-21 \mathrm{~cm}$ compr., densamente alveolada. Frutos ovais, $1 \mathrm{~cm}$ compr. $7,5 \mathrm{~mm}$ de diâm. Semente $7,5 \mathrm{~mm}$ compr. x $5 \mathrm{~mm}$ diam. Figura 4 A-E.

Material adicional: Brasil, Acre, Cruzeiro do Sul, Santa Luzia, SOUZA, M.C. et al., 551, 560, 12.III.2010, fr.; UFAC/Campus Floresta, Ferreira, J.G. et al., 12, 17.V.2011, fr.; SILVA, A.S. 01, 02.XII.2011, fr.; SOUZA, M.C. et al. 639, 19.I.2012, fr.; A.P.P. Croa, SOUZA, M.C. et al, 627, 30.XI.2011, fr.; Ramal 3, SILVA, L.C. 7, 8, 9, s/n 24.V.2012, fl. ; fr.; 17, 19, 20, 14.VI.2012, fl.. ; Rodrigues Alves, Comunidade Torre da lua, DAMACENO FILHO, 10, 11, 13, s/n. 21.I.2011, fl.. ; SOUZA, M.C. et al 562, 29.XI.2010, 
fr.; SOUZA, M.C. et al 579, 580, 28.XII.2010, fr.; Mâncio Lima, Comunidade Poyanawa, SOUZA, M.C. et al 572, S/N, 23.XII.2010, fr.

Estado de coleta: para esse morfotipo (Figura 4A-E), houve um acréscimo importante á coleção para a Região, registrando-se coletas pela primeira vez para o município de Rodrigues Alves. No passado a maioria das coletas foi proveniente de apenas dois municípios, Cruzeiro do Sul (HENDERSON, 1651, MAAS, P.J. 13268, $D A L Y, D . C$ et al. 11815, JANGOUX, J.J. 8505, 8529) e Mâncio Lima (HENDERSON, A. 1707, JANGOUX, 8575, PRANCE, 2801); e apenas um registro para Marechal Thaumaturgo (FERREIRA, E.117).

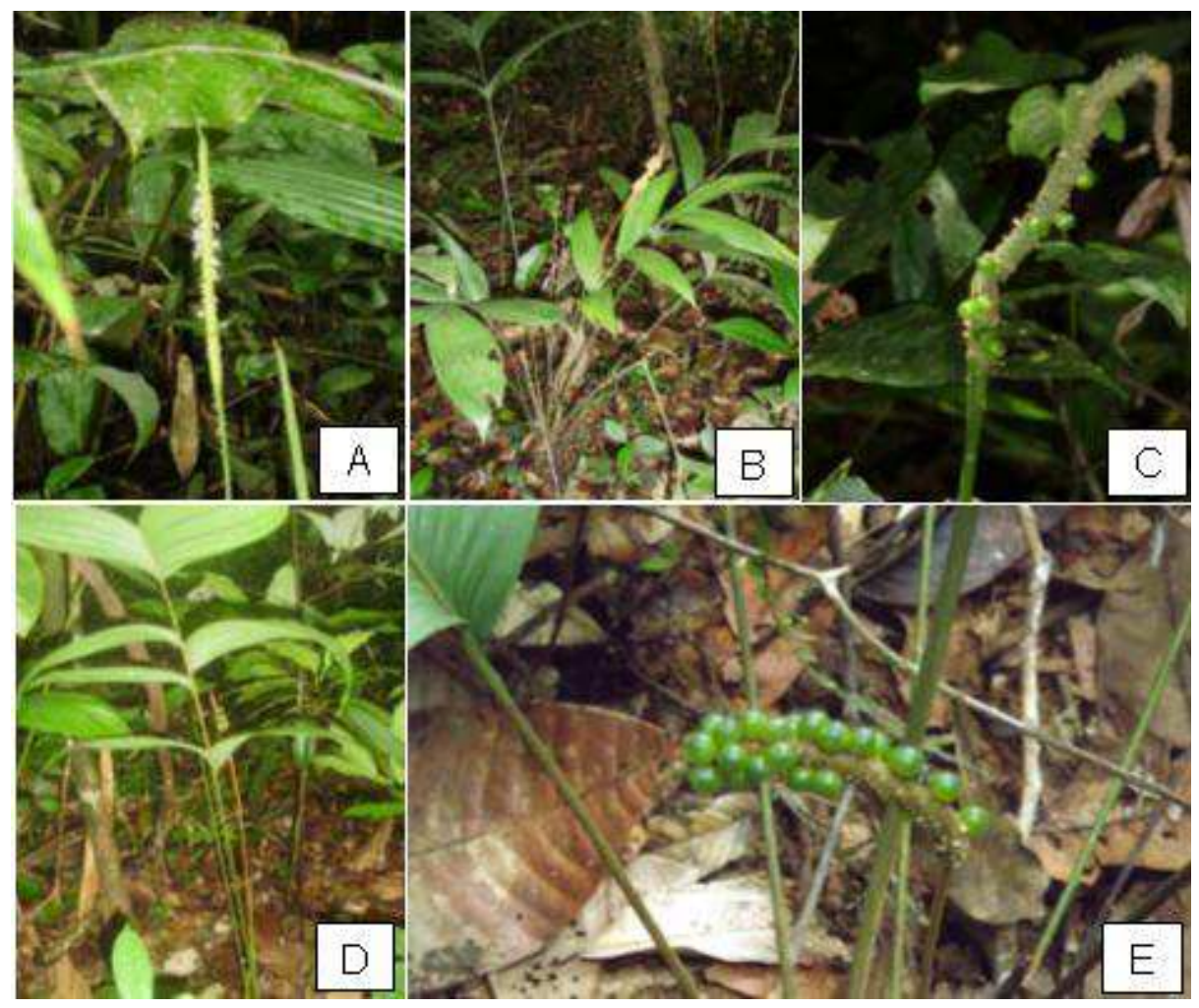

FIGURA 4. Geonoma macrostachys. Morfotipo II. A-E) Variações na forma da Inflorescência, Infrutescência e estágios de maturação

Morfotipo III. Planta com raízes expostas ou não; estipe quando presente, curtíssimo, $3,5 \mathrm{~cm}$ compr.; folhas, pinadas, 5 a 10 pinas por lado, levemente sigmóides, alguns indivíduos com pinas discolores, verde escuras na face adaxial e verde-amareladas na face abaxial; pina basal, 26, $5 \mathrm{~cm}$ compr., 4,5 cm larg., ângulo, 10ำ - 14웅 nervuras, 9, proeminentes na face abaxial, planas na face adaxial. Tomento, marrom por toda planta, estando ausente em alguns indivíduos. Pinas apicais mais largas, $27,5 \mathrm{~cm}$ compr., $7 \mathrm{~cm}$ larg. Infrutescências densamente alveoladas. Alvéolos distantes uns dos outros 3 - $4 \mathrm{~mm}$. Frutos, ovais, $8 \mathrm{~mm}$ compr., $5 \mathrm{~mm}$ diâm., imaturos verdes, maduros pretos. Figura 5A-D. 
Material adicional: Brasil, Acre, Alto Juruá, Rodrigues Alves, Torre da Lua, DAMACENO FILHO, J. et al., 09, SOUZA, M.C. et. al., s/n; Cruzeiro do Sul, Ramal 3, SILVA, L. C. 10, 11, 24.V.2011; A.P.P. Croa, SOUZA, M.C. et. al., 630, 30.XI.2011, fr; UFAC/Campus Floresta, SILVA, A.S. et al. s/n, 02.XII.2011, fl., SOUZA, M.C. 553, 639, 19.I.2012, fr.

Estado de coleta: $O$ presente estudo ampliou a coleção principalmente para o município de Cruzeiro do Sul. Para Rodrigues Alves foi registrada pela primeira vez. Coletas anteriores referem-se a dois municípios: Cruzeiro do Sul (MONTEIRO, O.P. 523; MAAS, P.J. 13024, PRANCE, G. 11835, 12092, JANGOUX, 8557; FERREIRA, E. 87; HENDERSON, A. 1122) e Mâncio Lima (HENDERSON, A. et al. 1115, 1121, SILVEIRA, M. et al. 1255).

Trata-se de um morfotipo extremamente variável, sendo incluídas aqui todas as variações que não se enquadram nos demais. Foram vistas plantas totalmente acaules, outras com estipe de $4 \mathrm{~cm}$ compr., com raízes expostas e muita variação no número de pinas, ocorrendo muito próximos, inclusive plantas com características morfológicas semelhantes a Geonoma brongniartii, mas a quantidade de plantas observadas foi pequena (Figura 5A-D). É preciso ampliar o esforço de coleta.

HENDERSON (2011) chama a atenção para esses casos intermediários que não se consegue definir. Essas variações não são apenas locais e as tentativas de entendêlas têm sido feitas ao longo do tempo. WESSELS BOER (1968) reconheceu três espécies e muita sinonímia, enquanto SKOV (1989) e Henderson et al (1995) reconheceram dentro desse complexo três variedades: $G$. macrostachys var. macrostachys, G. macrostachys var. acaulis e G. macrostachys var. poiteauana.

LORENZI et al (2010) não aceitaram tais variedades, concordando com WESSELS BOER (1968), mantendo como espécie, principalmente em função dos caracteres lâmina inteira, ângulo mais agudo entre a raque e nervura secundária, tamanho da inflorescência e a distribuição dos alvéolos para o primeiro táxon, além da preferência pela terra firme. Na revisão mais recente feita por HENDERSON (2011), uma das variedades foi reconhecida em nível de espécie - Geonoma poiteauana, e as demais foram consideradas morfotipos entre mais outros sete deles. Henderson (2011) quantificou diferentes variáveis, principalmente, tamanho e forma da folha, percebeu ainda que variações nas flores estaminadas podem auxiliar no entendimento desse complexo, mas não encontrou amostras nesse estágio em número suficiente.

Observou-se que os morfotipos I e II ocorreram muito próximos, em ambientes ocasionalmente alagados, podendo ser um fator relevante. A preferência desses morfotipos por ambientes específicos também é relatada em outros estudos realizados na Amazônia Ocidental, confirmando tais preferências pelo menos em nível local (KNUDSEN, 2002; VORMISTO et al. 2004; RONCAL, 2006). 


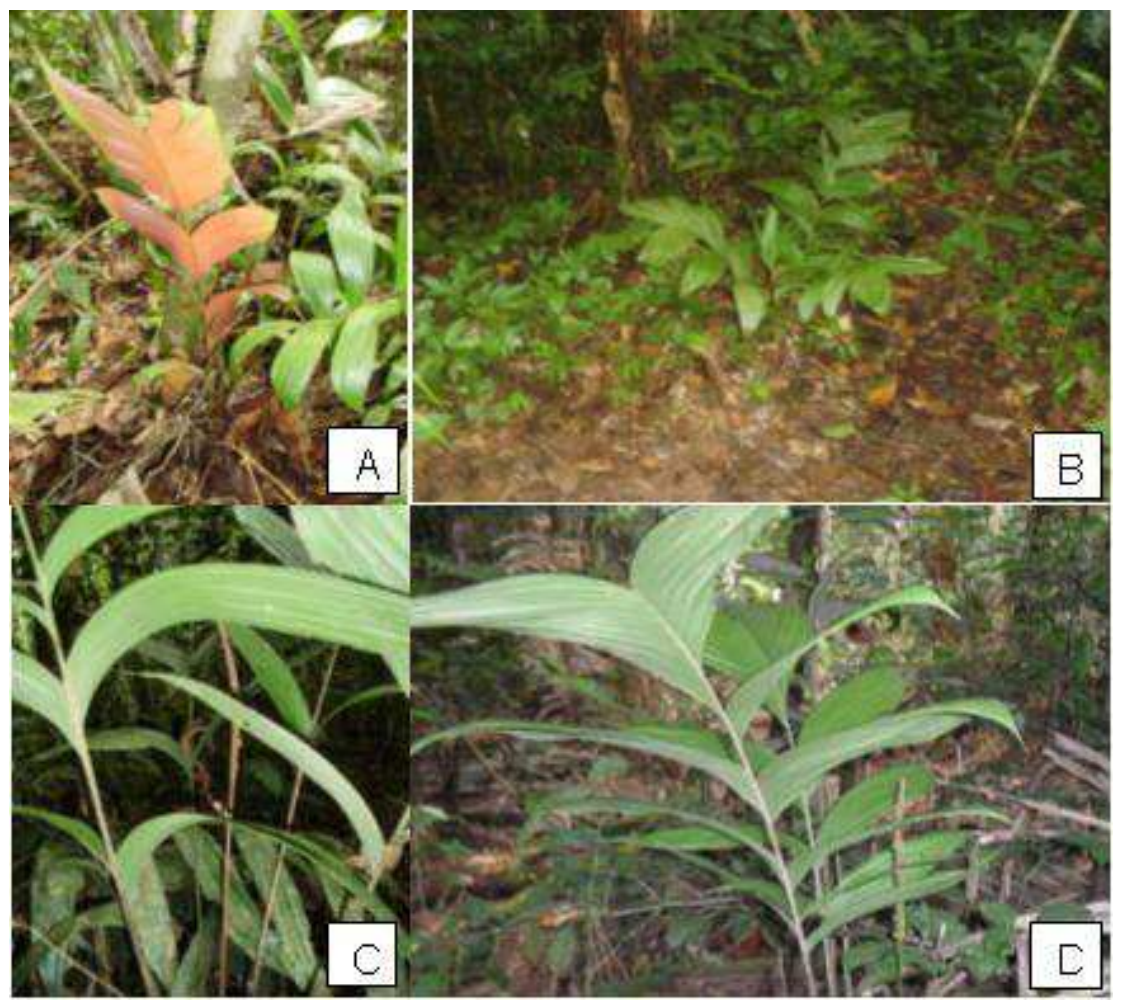

FIGURA 5. Geonoma macrostachys. Morfotipo III. A-D. Variações na forma e tamanho das pinas.

4. Geonoma brongniartii Mart. Voyage dans l'Amérique Méridionale 7(3): 24, pl. 12. 1843. (Voy. Amér. Mér.).Tipo: Bolivia: Yuracares, s.d, A. d’Orbigny 39 (P).

Palmeira, estipe curto, $10 \mathrm{~cm}$ alt., solitário, $5 \mathrm{~cm}$ circunf., raízes expostas. Folhas, 12 , pinadas, 3 - 18 pinas por lado, largas; verde-oliva, basal, $32,5 \mathrm{~cm}$ compr., $5 \mathrm{~cm}$ larg., central, $42,5 \mathrm{~cm}$ compr. $9,5 \mathrm{~cm}$, larg., apical, $45 \mathrm{~cm}$ compr., $11,5 \mathrm{~cm}$ larg. Nervuras proeminentes na face abaxial, tomentosas, em maior quantidade na nervura principal. Ângulo $5^{\circ}$. Inflorescência avermelhada, ráquila com parte apical finamente apiculada, $3,5 \mathrm{~cm}$ compr., brácteas, 2, basal, $17,5 \mathrm{~cm}$, apical, $23,5 \mathrm{~cm}$. Pedúnculo, $23,5 \mathrm{~cm}$ compr., raquila, $20 \mathrm{~cm}$ compr., alvéolos arranjados espiraladamente, $2-3 \mathrm{~mm}$ distantes um do outro. Flores, ca. 3,5 mm compr., 2,5 mm larg. Figura 6A-B.

Material adicional: Brasil, Acre, Cruzeiro do Sul, Ramal 3, SILVA, L.C. 12, 24.V.2012 fr.; Marechal Thaumaturgo, Comunidade Flora, SOUZA, M.C. $\mathrm{s} / \mathrm{n}$, 07.VIII.2011, fr.

Estado de coleta: trata-se de uma planta de pouca ocorrência na Região. Foi registrada nesse levantamento apenas para Cruzeiro do Sul. Duas plantas foram vistas fora do estágio reprodutivo (FIGURA 6A-B). O banco de dados virtual (inct.splink.org.br) 
assinala apenas um espécime (DALY, D.C. 11724) para o referido município, mas não disponibiliza imagem.

Há dois registros para Porto Walter (HENDERSON, A. 1652, E. FERREIRA, 173), constando na etiqueta de um deles como sendo do munícipio de Rodrigues Alves, o que não procede, a localidade "Natal" pertence a Porto Walter. Para Rodrigues Alves há registro de fato de um espécime (HENDERSON, A. 1649), com outro equívoco de localidade, constando na etiqueta como sendo de Cruzeiro do Sul. As demais coletas foram feitas em Marechal Thaumaturgo (DALY, D.C. 10423, 10947, 10582, 10550, 10716, FERREIRA, E. 112,113) e pela quantidade de exemplares observada, se supõe que seja muito comum ali. Percebe-se, ainda assim a necessidade de novas investidas na mata dos demais municípios.

A planta apresenta variações morfológicas de acordo com o local de ocorrência e por isso exige outras observações. No município de Cruzeiro do Sul, foi vista com três pinas por lado, largas, mas também numerosamente pinada. Já em Marechal Thaumaturgo foi registrada com apenas três pinas por lado; também se observou variação no tamanho do estipe.

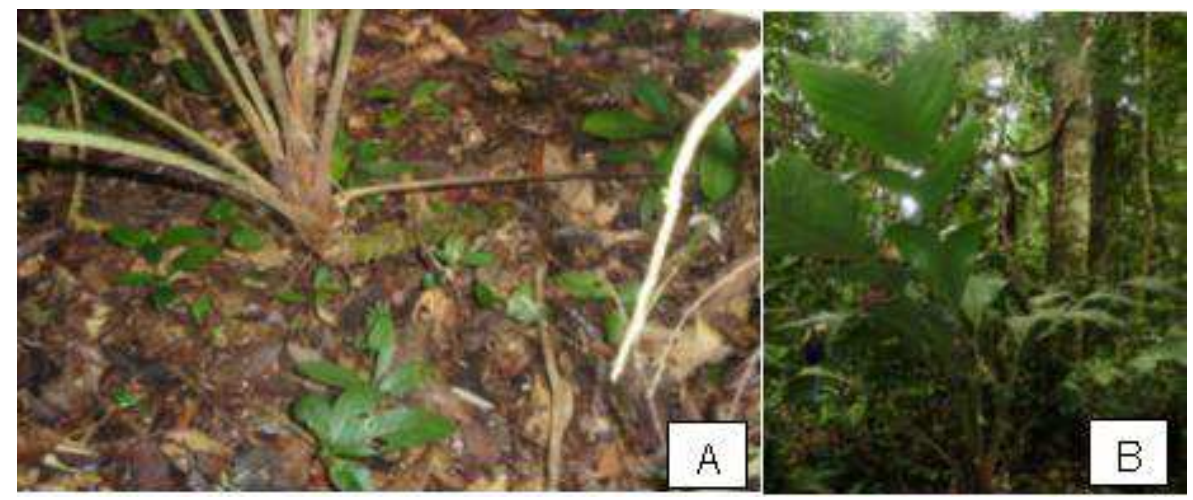

FIGURA 6. Geonoma brongniartii. A-D). A) Em evidencia o estipe curto e variações na forma e tamanho das pinas.

5. Geonoma camana Trail. Journal of Botany, British and Foreign 14: 324. 1876. (J. Bot.) Isótipo: Brasil. Rio Javari, 04.XII.1874, Trail 977/CLXXXII (P)

Planta, 2 - $3 \mathrm{~m}$ alt.; folhas, 1,8 - $2 \mathrm{~m}$ compr., pinadas, 36 por lado, dispostas regularmente no mesmo plano, a pina apical geralmente mais larga. Face adaxial das pinas verde-claras, brilhosas, face abaxial, verde-escuras. Raque, 1,12 m de compr. Infrutescência espigada, interfoliar, $66 \mathrm{~cm}$ de compr. Frutos elipsoides, $9 \mathrm{~mm}$ de compr., 5 mm diâm., negros (Figura 7A-D).

Material adicional: BRASIL, Acre, Cruzeiro do Sul, Campus Floresta, FERREIRA, J.G. 15, fr. 31.I.2014; Assentamento Santa Luzia, MENDONÇA, K.C.B. 09, fr., 24.V.2011.

Estado de coleta: Nesse estudo a planta foi coletada pela primeira vez para o município de Cruzeiro do Sul; registros anteriores apontam para Mâncio Lima 
(FERREIRA, E. 111, SILVEIRA, M. et al. 1253, LORENZI, H. et al. 3717; HENDERSON, A., 1106, 1128, 1680, 1690, JANGOUX, J.J. 8570, 8576), Marechal Thaumaturgo (FERREIRA, E. 125, 136,163, 165) e Porto Walter (HENDERSON, A. 1661).

No sub-bosque, a planta se distingue, pelas pinas estreitas e espessas, relativamente curtas e brilhosas e também pela forma e localização da infrutescência. As consultas aos herbários virtuais revelaram que plantas identificadas como sendo $G$. camana, apresentam semelhança com G. macrostachys. HENDERSON (2011) chama a atenção para algumas variações encontradas no Acre, sugerindo plantas intermediárias entre os táxons em questão.

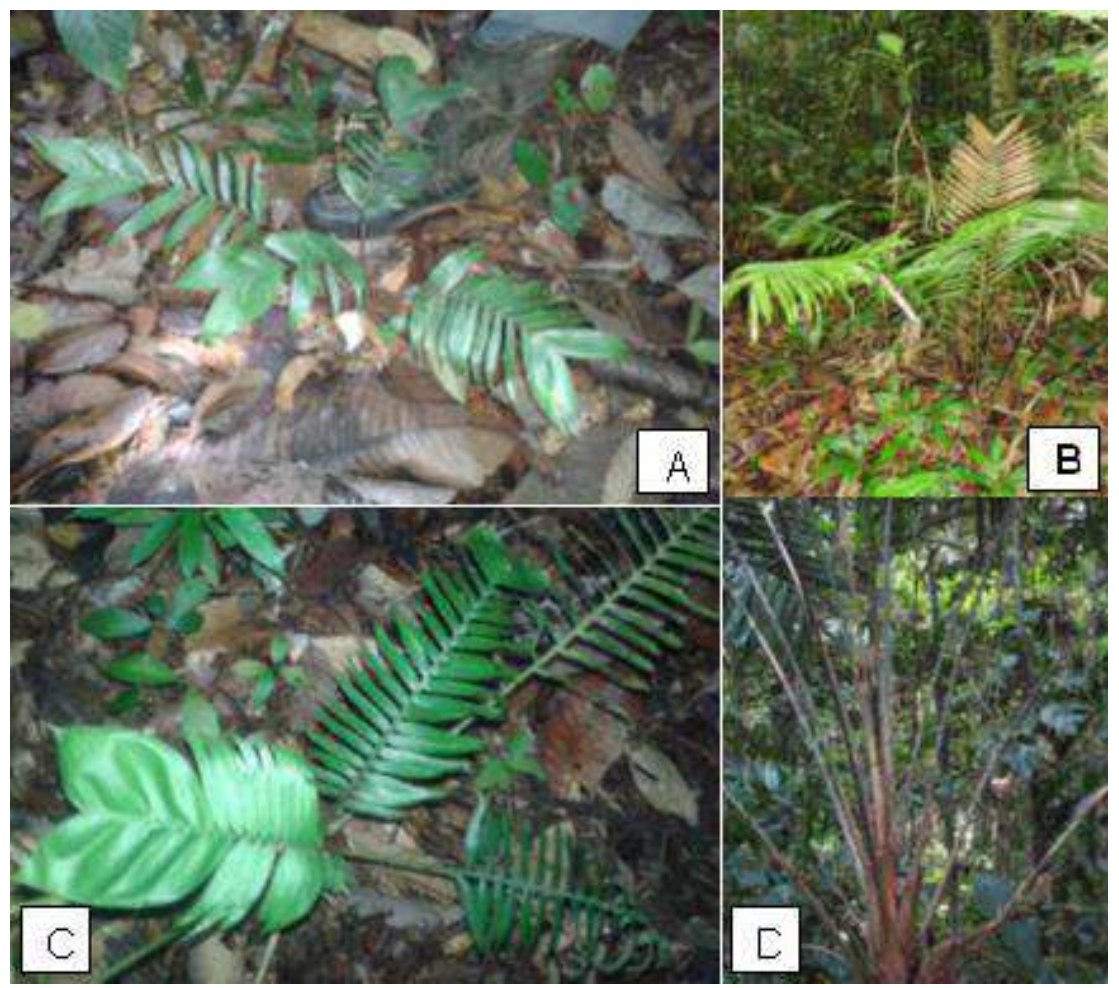

FIGURA 7. Geonoma camana. A-C) Variações na morfologia foliar ao longo do crescimento; D) Planta em estágio reprodutivo, presença de infrutescência espigada.

6.Geonoma deversa (Poit.) Kunth Enumeratio Plantarum Omnium Hucusque Cognitarum 3: 231. 1841. (Enum. PI.) Tipo: Guiana Francesa. Sem localidade, sem data. A. Poiteau, s.n. (P).

Palmeira, 2 - $3 \mathrm{~m}$ altura. Estipe solitário ou cespitoso, 4 - $5 \mathrm{~cm}$ circ. Folhas, 3 - 4 pinas, sigmoides, pina basal, $28 \mathrm{~cm}$ compr., $5 \mathrm{~cm}$ larg.; pecíolo, $22 \mathrm{~cm}$ compr.; bainha, $15 \mathrm{~cm}$ compr., raque, $58 \mathrm{~cm}$ compr., (algumas plantas com folhas numerosamente pinadas). Ângulo, $10^{\circ}$. Tomento marrom ao longo das nervuras na face abaxial das pinas e ao longo das ráquilas. Inflorescência densamente coberta com tomento marrom. Ráquilas 12 , ramificação de $2^{a}$. ordem, amarelas na fase de flores e alaranjadas na fase de fruto, alvéolos, 1 - 1,5 mm distantes um do outro, opostos ou raramente verticilados. 
Também sendo possível ráquilas com alguns alvéolos alternos, próximo a parte apical. Frutos, globosos, $7 \mathrm{~mm}$ compr., $6,5 \mathrm{~mm}$ diâm., imaturos verdes, maduros pretosamarronzados (Figura 8A-D).

Material adicional: Brasil, Acre, Cruzeiro do Sul, UFAC/Campus Floresta, SOUZA, M.C. 554, 14.XI.2010, fr. Assentamento Santa Luzia, SOUZA, M.C. et al., 565, 06.XII.2010, fl. UFAC/Campus Floresta, FERREIRA, J.G. et al., 01, 18.IX.2010, fl. ${ }^{\lambda}$, fr., 09, 20.IV.2011, fr. Assentamento Santa Luzia, MENDONÇA, K.B. s/n., 05, 06, 18.II.2011; Ramal 3, SILVA, L.C. 05, 24.V.2012, fl.; fr. Mâncio Lima, Comunidade Poyanaua, SOUZA, M.C. et al., s/n, 574, 23.XII.2010, fr.

Estado de coleta: Houve um incremento na coleção dessa espécie, principalmente para Cruzeiro do Sul, se observando em uma das localidades visitadas sua ocorrência em densas populações. Foi registrada também para Mâncio Lima. Estudos anteriores registraram para os mesmos municípios, Mâncio Lima (PRANCE, G.T. 2838, JANGOUX, J. 8570, HENDERSON, A. 1100, 1102, 1143, 1679, 1684, 1705), Cruzeiro do Sul (JANGOUX, J. 8528, FERREIRA, E. 181, HENDERSON, A. 1673, CROAT, T.B. 85561, 85555, PRUSKI, J.F. 3484) e apenas um espécime para Marechal Thaumaturgo (FERREIRA, E. 131).

Uma localidade visitada chamou a atenção pela ocorrência de densas populações desse táxon, mas quando comparada em relação a outros locais visitados, ela é bem menos comum na Região que G. macrostachys. G. deversa é de fácil identificação no interior da mata, mas ainda assim, semelhante ao já mencionado para G. maxima subsp. chelidonura, se observa erro de identificação nos herbários sendo confundida com Hyospathe elegans, principalmente na forma das pinas (Figura 2 e 8C). Porém as três pinas por lado e a inflorescência ramificada com alvéolos bifídos ou trífidos, são bem característicos. Muito raramente encontrada tendo folhas com mais de três pinas e alvéolos verticilados, ou ainda da metade da raquila até a parte apical, com alvéolos espiralados. HENDERSON (2011) assinala essas e outras variações e reconheceu após examinar caracteres de 179 exemplares, a ocorrência de quatro subespécies, e tira o status de espécie de Geonoma myriantha, passando a ser sinônimo de uma das subespécies - Geonoma deversa subsp. deversa. 


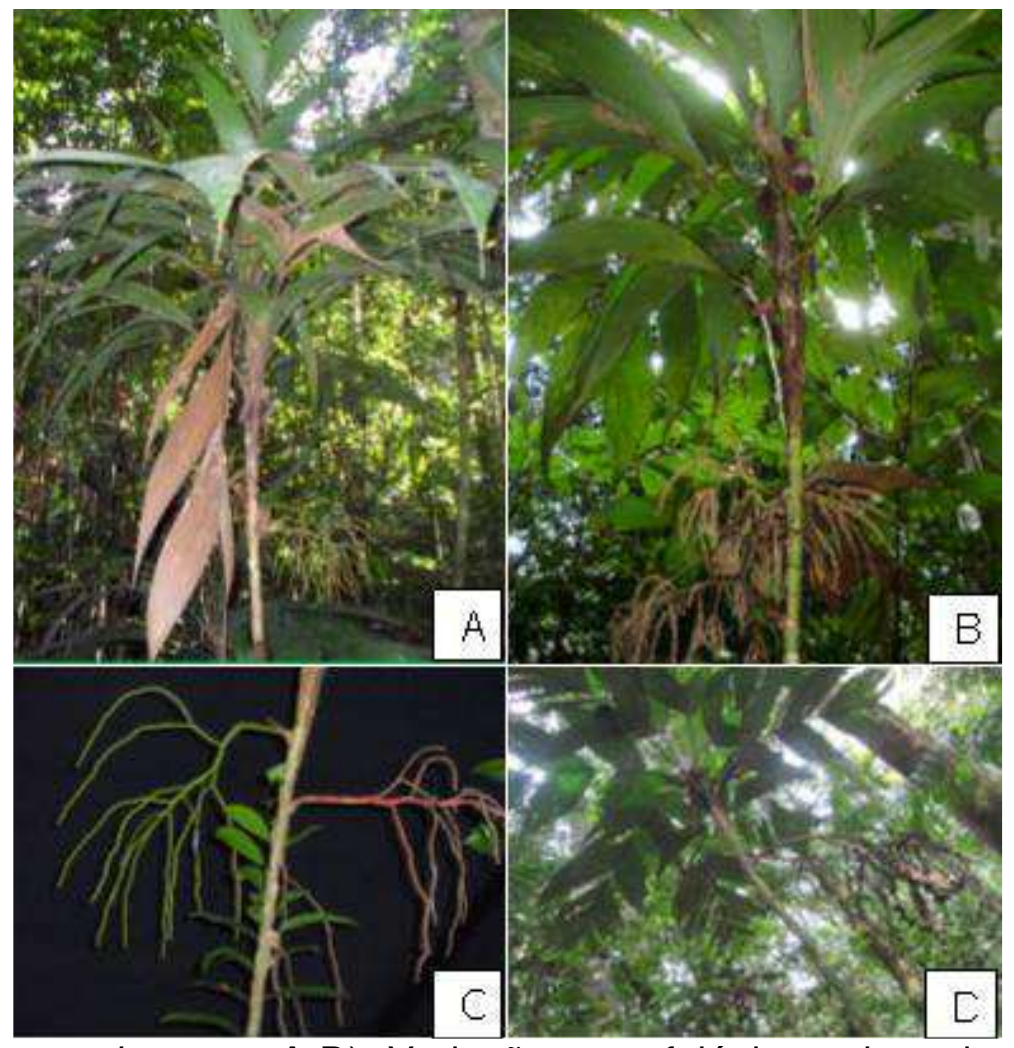

FIGURA 8. Geonoma deversa. A-D) Variações morfológicas das pinas foliares e estágios de desenvolvimento das inflorescências e infrutescências.

7.Geonoma stricta subsp. arundinacea (Mart.) A.J.Hend. Phytotaxa 17: 144-145, f. 38. 2011. Basiônimo. Geonoma arundinacea Mart. Historia Naturalis Palmarum 2: 17, pl. 18. 1823. (Hist. Nat. Palm.) T: Brasil. Amazonas: s.l., s.d. C.Martius s.n (M)

Palmeira, $1,5 \mathrm{~m}$ alt., estipe solitário, $2 \mathrm{~cm}$ circunf., amarelo-esverdeado. Folhas, inteiras ou pinadas, 3 - 5 pinas por lado, sigmóides, pecíolo, $12 \mathrm{~cm}$ compr., pina basal, 3 - 20,5 cm compr., 5,3 cm larg.; raque, $9-30,7 \mathrm{~cm}$ compr. Bainha, $5-9 \mathrm{~cm}$ compr. Ângulo, $10^{\circ}-13^{\circ}$. Nervuras planas ou sobressaindo-se nas duas faces, cobertas com tomento marrom, em maior densidade na nervura principal. Inflorescência, ereta, curta ou longa, infrafoliar. Bráctea, $7 \mathrm{~cm}$ compr., pedúnculo, $4-6,2 \mathrm{~cm}$ compr., ráquila, 6 $29,5 \mathrm{~cm}$ compr., densamente alveolada. Flores, 3,5 - $4 \mathrm{~mm}$ compr., $3 \mathrm{~mm}$ larg., frutos jovens verde-amarelados, ovais, maduros azuis, $7-12 \mathrm{~mm}$ de compr. $5-9 \mathrm{~mm}$ larg. Figura 9.

Material adicional: Acre, Mâncio Lima, Barão, Terra Poyanaua, SOUZA, M.C. 550 et al., 22/I/2010, fr.; Cruzeiro do Sul, UFAC/Campus Floresta, FERREIRA, J.G. 07,

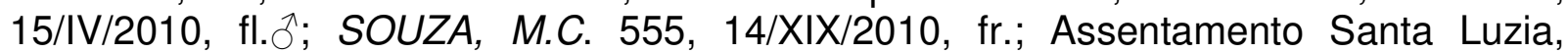
SOUZA, M.C., 552, 12/ll1/2010, fl. ,ffr. Assentamento Santa Luzia, SOUZA, M.C. 593, 06/V/2011, fl. ${ }^{\text {, }}$, Ramal 3, SILVA, L.C. 03, 06, 07 24/V/2012, fr. 


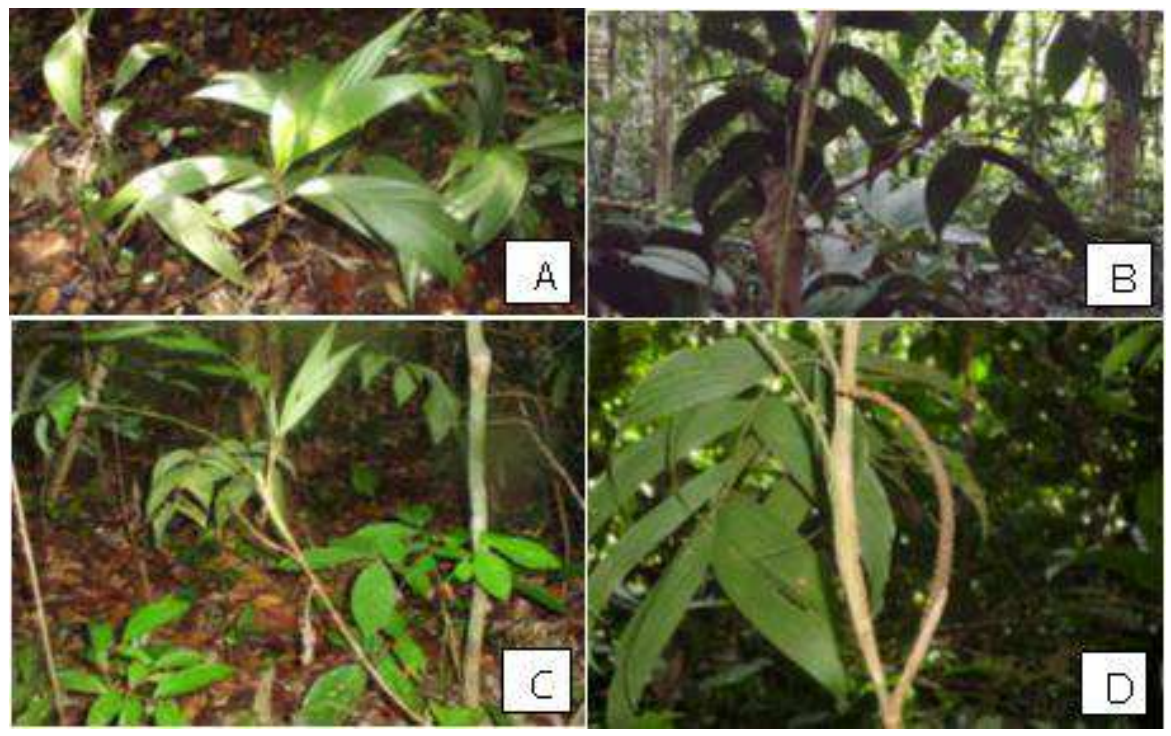

FIGURA 9. Geonoma stricta subsp. arundinacea. A-D) Hábito, variações na morfologia das pinas, e Infrutescência espigada.

Estado de coleta: o presente estudo permitiu um incremento para os municípios de Cruzeiro do Sul e Mâncio Lima, com algumas localidades visitadas pela primeira vez. Os herbários online consultados revelaram exemplares de Mâncio Lima (PRANCE, G.T.12093, HENDERSON, A.1105, 1108, 1679,1114, 1132, 1143, 1700, 1682, MAAS, P.J.M. 12704, FERREIRA, E. 182,185), Cruzeiro do Sul (CROAT, T.B. 62624, JANGOUX, J. 85001, 85030, 85050, FERREIRA, E. 104, DALY, D.C. 11706), Porto Walter (CROAT, T.B. 85141, HENDERSON, A.1668) Marechal Thaumaturgo (DALY, D.C.10466, FERREIRA, E. 161) e Guajará (FERREIRA, E. 104).

Aqui com base em apenas observações no campo e de alguns exemplares, se supõe a ocorrência de duas plantas com diferenças marcantes em locais muito próximos, uma com folhas grandes, pinadas, nervuras sobressaindo-se, inflorescência espigada, longa, ereta; e outra de folhas inteiras, pequenas, nervuras planas, inflorescência espigada, curta e ereta; ambas com flores estaminadas persistentes. Muita variação! HENDERSON (2011) reconheceu a subespécie e novas combinações em função do estudo das variações do ponto de vista qualitativo e quantitativo, e o que antes tinha status de espécie - Geonoma piscicauda (LORENZI et al, 2010) ou variedade - Geonoma stricta var. piscicauda (HENDERSON et al, 1995) o autor enquadrou como mais um dos morfotipos possíveis da subespécie encontrada. Com base em apenas variáveis quantitativas, HENDERSON \& MARTINS (2002) já haviam verificado também que a categorização de variedades era inconsistente.

Conclui-se que levantamento permitiu refazer e atualizar coletas, com visita a lugares para os quais não havia registro, e, ao mesmo tempo ampliar a coleção do Herbário local (HUFAC-CZS). 


\section{REFERÊNCIAS}

BURRET, M.1930. Geonomeae Americanae. Botanische Jahrbücher für Systematik 63: $123-270$

BROWN JR, K.; FREITAS, A.V.L. Diversidade biológica no Alto Juruá: avaliação, causas e manutenção. p.33-63. IN: CUNHA, M.C.; ALMEIDA, M.B. Orgs. Enciclopédia da Floresta. $O$ Alto Juruá: práticas e conhecimentos das populações. São Paulo: Companhia das Letras, 735p. 2002.

DALY, D.C.; SILVEIRA, M. Primeiro catálogo da flora do Acre, Brasil. Rio Branco, AC: EDUFAC, 555p. 2008. Disponível em: http://botanica.sp.gov.br/semcategoria/primeiro-catalogo-da-flora-do-acre-brasil/

HENDERSON, A. J. 1995. The palms of the Amazon. Oxford University Press, New York. 362 pp.

HENDERSON, A. 2011. A revision of Geonoma (Arecaceae). Magnolia Press, Auckland, New Zealand. Phytotaxa 17: 1-271 Disponível em: http://www.mapress.com/phytotaxa/content/2011/f/pt00017p271.pdf DOI:.org/10.11646

HENDERSON, A.; GALEANO, G.; BERNAL, R. Field guide to the Palms of the Americas. New Jersey. 1995. $352 \mathrm{p}$.

HENDERSON, A.; MARTINS, R. 2002. Classification of specimens in the Geonoma stricta (Palmae) complex: the problem of leaf size and shape. Brittonia 54: 202-212. Disponível em: https://www.jstor.org/stable/3218402 DOI: 10.1007/s12228-015-9370-8

HOLMGREN, P.K.; N. H. HOLMGREN, L. C. BARNET. 1990. IndexHerbariorum: part I: The Herbaria of the World. 8th ed. New York: International Association for Plant Taxonomy. 683 pp. Disponível em: https://www.nybg.org/images/scientists/8NoelHolmgren_CV.doc DOI:10.1111/j.1756-1051.1983.tb01945.

LORENZI, H.; NOBLICK, L.R.; KAHN, F.; FERREIRA, E.J.L. Flora brasileira: Arecaceae (palmeiras). Nova Odessa, SP: Instituto Plantarum, 2010. 368p. Disponível em: https://www.plantarum.com.br DOI:10.15468/ymks0x

RONCAL, J., FRANCISCO-ORTEGA, J. \& LEWIS, C. (2007). An evaluation of the taxonomic distinctness of two Geonoma macrostachys (Arecaceae) varieties based on inter simple sequence repeat (ISSR) variation. Botanical Journal of the Linnaean Society 153: 381-392. Disponível em: on line library.wiley.com/doi/10.1111/j.1095...2007...x DOI: 10.1111/boj.1095.

SKOV, F. 1989. Hipertaxonomy - a new computer, tool for revisional work. Taxon. 38(4): $582-590$ 
VORMISTO, J., TUOMISTO, H. \& OKSANEN, J. (2004) Palm distribution patterns in Amazonian rainforests: What is the role of topographic variation? Journal of Vegetation Science 15: 485-494. Disponível em:

https://www.researchgate.net/.../227668076_Palm_distribution_patterns_in_Amazonian _...DOI: $10.1111 /$ jvs.12541.

WESSELS BOER, J.1968. The geonomoid palms. Verhandelingen der Koninklijke Nederlandse Akademis van Wetenschappen. Tweede Reeks 2(58): 1-202 